\title{
Tensiones entre singularidad y subjetividad en un hospital psiquiátrico de Quito/Ecuador
}

\author{
MALENA BATTISTA \\ Investigadora Independiente | Quito, Ecuador \\ malenabattista@gmail.com
}

DOI 10.11606/issn.2316-9133.v30i2pe187778

resumen En este artículo presentaré un análisis antropológico que busca reconocer las distintas formas en que los procesos de subjetivización y de singularización se encuentran en constante tensión dentro del Hospital Especializado Julio Endara de Quito. Para ello me basaré en el trabajo etnográfico realizado en el marco del taller de títeres y relatos de vida propuesto a residentes del hospital y que operó como lugar del trabajo de campo. El mismo arroja luz sobre la superposición de exclusiones raciales, clasistas, de género y del mundo de la razón, vivenciadas por pacientes psiquiátricos. Elaboro el concepto de relatos otros a través del cual identifico los procesos de singularización, en la transición entre distintos lenguajes, sustratos y herramientas de elaboración. Espero presentar una mirada antropológica sobre el mundo de la salud mental, un abordaje integral y situado capaz de ofrecer, en clave transdisciplinaria, alternativas a las lógicas de la manicomialización que aún imperan dentro y fuera de los hospitales psiquiátricos.

palabras claves subjetividad; singularidad; salud mental; etnografía; hospital psiquiátrico
Tensiones entre singularidad $y$ subjetividad en un hospital psiquiátrico de Quito/Ecuador

abstract The article presents an anthropological analysis that seeks to recognize the different ways in which the processes of subjectivization and singularization are in constant tension. It is based on the ethnographic research carried out in the framework of a puppet and life stories workshop with residents of the specialized hospital Julio Endara, in Quito/Ecuador. It sheds light on the overlapping of racial, class, gender and reason exclusions experienced by psychiatric patients. It also presents the concept of other narratives through which is identified the processes of singularization, in the transition between different languages, substrates and tools of elaboration. The article hopes to present an anthropological view of the world of mental health, an integral and situated approach capable of offering, in a transdisciplinary key, alternatives to the logics of psychiatric mental health that still prevail inside and outside psychiatric hospitals.

keywords subjectivity; singularity; mental health; ethnography; psychiatric hospital 


\section{Introducción}

Mi interés en las relaciones de saber-poder-sujeto, los procesos de tensión entre subjetividad y singularidad, y la relación entre procesos artísticos y comunicacionales con el campo de la salud mental, nace durante mi trayectoria como voluntaria del colectivo de comunicación y cultura El Cisne del Arte de la ciudad de La Plata (Argentina) y mi intervención como antropóloga visual en procesos de salud mental comunitaria con usuarios de salud mental del Hospital Neuropsiquiátrico Dr. Alejandro Korn (Buenos Aires). Durante mi estadía en Quito, entre el 2018 y el 2020, fue posible conocer el Hospital Especializado Julio Endara, vincularme con algunos residentes de este y observar ciertas prácticas discursivas y extradiscursivas que hablaban de un fuerte ejercicio del poder psiquiátrico y de otros dispositivos de control basados en el racismo y la desigualdad de género. A partir de esta experiencia formulé las siguientes preguntas: ¿Quiénes son los sujetos que residen en el hospital como pacientes psiquiátricos? ¿cuáles son los lenguajes a través de los cuales construyen su singularidad? De esta forma propuse realizar un taller dentro del hospital donde poder explorar a través de la antropología distintos procesos de singularización junto a los y las residentes, y observar en profundidad los procesos de subjetivización normados que pudieran estar operando.

En su interés por la constitución de los sujetos y su relación con los procesos de control social, Foucault llamó dispositivos de poder al entramado de discursos y prácticas extradiscursivas que producen en su seno sujetos, es decir, que conforman procesos de subjetivización orientados por la norma y el disciplinamiento (2008a; 2008b; 2015). Asociados a estos y otros procesos, Foucault desarrolla lo que él llama técnicas de control y disciplinamiento social, dos formas que adquiere el poder a partir del XVII: la anatomopolítica y la biopolítica $(1999 ; 2005 ; 2007)$. Este nuevo tipo de poder se orienta por gobernar la vida en todos sus aspectos, donde la muerte se haya "recubierta por la administración de los cuerpos y la gestión calculadora de la vida" (Foucault, 1999: 84). Como corolario, el poder se centró en la (in)corregibilidad de los sujetos (Foucault, 1999; 2005). A través de lo que Foucault llama el dispositivo psiquiátrico, se construirá la noción de enfermedad mental, la necesidad de analizar a profundidad la psiquis y de curarla, la relación de dependencia de pacientes a médicos, y el disciplinamiento psiquiátrico como solución a esta problemática. La relación entre poder y saber dará lugar a la creación de sujetos susceptibles de ser analizados individualmente bajo la sospecha de normalidad/anormalidad, controlados poblacionalmente y, aquellos que no se adapten y que representan un "peligro" para la sociedad, encerrados en estas instituciones.

La idea del sujeto creado en el seno de las relaciones de poder y discursos de saber dejaba un sentido muy pesimista sobre la constitución de los sujetos (Vignale, 2014). Algo que el mismo autor se encargó de revertir y profundizar a partir de Historia de la Sexualidad II (2003), donde planteó que los procesos de subjetivización no se dan únicamente bajo la ejecución de la norma sino en el fuego cruzado entre las técnicas de disciplinamiento, y las técnicas de reconocimiento de sí. En Tecnologías del yo (2008b) Foucault posará su mirada en las artes de la existencia propias de la antigüedad grecorromana, prácticas de reconocimiento de sí que conferían una experiencia de transformación y de un halo estético a las vidas de 
quienes las practicaban. Demostrando el interés del autor por comprender qué otras formas existen y podemos crear, para constituirnos como sujetos éticos, más allá de los efectos de la norma (2008a). Idea fundamental para responder la pregunta sobre quiénes son los sujetos que residen en el hospital: ¿son sujetos en la medida que se insertan en relaciones de poder y son atravesados por discursos de saber, o lo son también en una forma singular que los diferencia entre sí a la vez que los dispone en comunidad?

Según Deleuze (2015), en el paso que realiza Foucault del estudio de la época clásica a la antigüedad grecorromana, el autor comprende que los primeros en constituir la idea del yo y de construir el pliegue de la subjetividad, son los griegos. La idea de pliegue proviene del Pensamiento del afuera (Pelbart, 1989), una línea filosófica que plantea el pensamiento como una forma de relacionarnos y abrirnos a un afuera, a las relaciones y la diferencia, en vez de un cerrarse sobre nosotros mismos.

En esta corriente filosófica, la subjetividad es el pliegue de la diferencia, una manera singular de plegar este afuera (Deleuze, 2015). Ya en el sistema capitalista la subjetivación pasa a ser reinsertada en las relaciones de poder, y la ética de sí es invadida por el saber. El sujeto se vuelve sobre sí mismo y nace la individualidad como forma de subjetividad normada (Deleuze, 2008). Si bien, hoy día los procesos de subjetivación se ven atados a las relaciones de poder e investidos por el saber, surgen constantemente nuevos pliegues, nuevas formas de constituirse en sujetos que escapan y resisten a estos ejes (Deleuze, 2015).

Lejos del concepto de individualidad, producto de la subjetivización en masa, los procesos de singularidad constituyen otras formas de pensar, otras formas de crear y de relacionarnos con otros o con lo otro, respecto de los procesos de subjetivación capitalísticos (Guattari y Rolnik, 2006).

El presente artículo caracteriza las distintas formas en que los procesos de subjetivización y de singularización se encuentran en constante tensión dentro del Hospital Especializado Julio Endara, a través de algunas experiencias vivenciadas en el marco del trabajo etnográfico ya citado. La propuesta metodológica de la investigación antropológica se orientó por la búsqueda, el reconocimiento y la puesta en valor de aquellos procesos de singularización que ofrecen resistencia y proponen nuevas disposiciones frente a los procesos de normativización e individuación que existen dentro del hospital psiquiátrico. La propuesta transversaliza herramientas tales como la metodología de taller, la creación de relatos de vida, la construcción y teatralización con títeres, y la etnoficción.

El apartado etnográfico presenta a los y las participantes del taller y retoma algunas experiencias dentro y fuera del mismo vinculadas a procesos de subjetivización propios del dispositivo psiquiátrico, así como también la intersección de este dispositivo junto a otras prácticas discursivas y extradiscursivas provenientes del sistema colonial-hacendatario y de género. Los relatos de mis interlocutores permitieron ver capas de la experiencia colonial actualizada en sus experiencias y también en las prácticas cotidianas de la institución psiquiátrica. Pero también, permitieron reconocer las singularidades que generalmente no son valorizadas y que pueden ser una vía para posicionar a los sujetos como agentes de cambio. 
Como resultado del análisis antropológico y la metodología propuesta, propongo pensar los procesos de singularización acontecidos en el marco de este trabajo etnográfico como relatos otros, dando cuenta de las distintas formas de relatar estas otras formas de ser, hacer y relacionarnos con otros respecto a los procesos de subjetivización capitalísticos (Guattari y Rolnik, 2006), marcando una diferencia con las narrativas institucionales.

Las personas atravesamos tanto procesos de subjetivización como de singularización, y en palabras de Guattari y Rolnik (2006), estos procesos de singularización pueden modificar las disposiciones de poder según los procesos de reconocimiento que los acompañen:

Cualquier emergencia de singularidad provoca dos tipos de respuesta micropolítica: la respuesta normalizadora o, por el contrario, la respuesta que busca encaminar la singularidad hacia la construcción de un proceso que pueda cambiar la situación, y tal vez no sólo localmente. (Guattari y Rolnik, 2006: 66).

Según Tim Ingold la antropología puede comprenderse como "art of inquiry", un concepto que establece pensar y sentir a través del hacer (2015). Pensarla como oficio y no como quehacer teórico, permite abrir la disciplina a un sentido transformacional de las realidades. En este sentido, este artículo busca construir una mirada antropológica sobre el campo de la salud mental y herramientas analíticas y de intervención local que permitan construir el proceso de transformación mediante el cual revertir las lógicas manicomiales que excluyen, aíslan y deterioran la vida de quienes ingresan a los hospitales psiquiátricos como pacientes.

\section{Metodología}

La experiencia etnográfica sobre la cual se basa este artículo consistió en una experiencia de campo, guiada por la observación participante, y elaborada en el marco de un taller de títeres y relatos de vida propuesto a personas que viven en el Hospital Especializado Julio Endara de Quito (de ahora en más HEJE) como pacientes psiquiátricos. El taller tuvo lugar durante los meses de febrero y marzo del año 2020 y participaron de manera regular Pablo, Cristina y Sylvia, los cuales presentan largos procesos de institucionalización, y son considerados "pacientes crónicos" dentro del hospital, y Marcia, una paciente de la "Sala de residentes". Cada uno de los participantes provenía de provincias diferentes a la de Pichincha (la provincia que alberga la capital de Ecuador, Quito), con una clara trayectoria rural y no capitalina, con intereses y formas de participar del taller diferentes entre sí, y marcados por distintos procesos de subjetivización dentro y fuera del hospital. El espacio se compuso de actividades tales como sesiones de expresión corporal, teatralización y construcción de títeres. El y las participantes fueron invitados a participar voluntariamente

\footnotetext{
${ }^{1}$ La sala de residentes es un sector dentro del hospital en donde duermen y realizan actividades residentes mujeres a las cuales se las considera con mayor autonomía que otros residentes del hospital y que tienen mayores posibilidades de externarse.
} 
y se les explicó desde el primer día que el espacio formaba parte de una investigación antropológica. Sus procesos de singularización fueron considerados bajo el concepto de "relatos otros", como resultado de la co-elaboración entre practica y teoría en el marco de la etnografía.

El taller se constituyó como mi lugar antropológico desde donde reconocer y dar valor a estos procesos de singularidad y desde donde observar críticamente y en clave antropológica los procesos de subjetivación que acontecen dentro del hospital. El planteo metodológico que acompañó y elaboró este espacio-tiempo, buscaba ponderar los procesos de singularización sobre los de subjetivización en los que la misma investigación podía incurrir.

La metodología desarrollada en un taller permite construir un espacio en donde prima la colectivización de los afectos, las creaciones, las historias personales, el sentido lúdico como organizador de las actividades y el vacío como lugar de las singularidades. Un espacio donde es posible desarrollar una etnografía basada en la observación participante y la exploración de la materialidad como vehículo para la producción de conocimiento (Ingold 2015), así como también un espacio de transformación y de corrimiento de los procesos de subjetivación individuantes. El taller es un espacio en donde los saberes de cada participante son puestos en juego a la vez que se elaboran nuevos en conjunto. Esto permite construir un vacío en donde puede ocurrir lo otro, es decir, un espacio-tiempo en donde las diferencias son alojadas (Lago, 2015). El carácter lúdico del mismo orienta la actividad cultural por el disfrute y, por lo tanto, solo puede darse de forma voluntaria (Lago, 2015).

En el marco de la psiquiatrización los relatos de vida acontecen y circulan constantemente como marcas de singularidad, sin embargo, muchas veces son descartados, negados o resignificados en el marco de las lógicas manicomiales. Los relatos de vida evocan necesariamente a un otro, toda vez que el lenguaje que utilizamos no nos pertenece y que nuestra singularidad es inabarcable (Butler, 2009). Los relatos de vida evocan experiencias de vida y repertorios culturales que tienen un impacto social ineludible, y relatarlos frente a otro nos permite colectivizar la experiencia y convertirse en un factor de reparación social (Jelin, 2002). La escucha atenta y la relación ética que se establece con el otro, debe realizar una vigilancia constante para que la relación establecida en el relato no se vuelva normativizante. Esto implica no realizar operaciones de veridicción, ni catalogar al otro en roles o definiciones estáticas e individualizantes. Con relación a esto, Bourdieu explica que la idea de linealidad narrativa supone tácitamente un sujeto coherente en tiempo y forma a lo largo de toda su experiencia de vida, y que los relatos, para que sean "verdaderos", deben presentar una línea histórica de acontecimientos sucesivos (Bourdieu, 2011). Esto supone que la vida es un conjunto de acontecimientos cronológicos, coherentes y asociados a una única versión de nosotros mismos (Bourdieu, 2011). Si la escucha es un acto activo y empático, dispuesta sobre un amplio margen de creatividad, el reconocimiento de los sujetos pondera por sobre el reconocimiento y la imposición de la norma (Butler, 2009).

La elección de trabajar con el armado y teatralización con títeres surge a partir de dos cuestiones: una, la necesidad de trabajar los procesos de singularización y la creación de relatos de vida a través de la materialidad y la creación artística. El arte no puede definirse 
por la huella individual sino como un proceso relacional, algo que nos pone en relación con otros durante y después del proceso creativo (Bourriaud, 2008), no puede definirse sino es por la huella de transformación colectiva. En la misma línea, Tim Ingold considera la antropología como un "art of inquiry" por su capacidad transformacional, planteando una relación directa entre arte y antropología (2015), donde "el encuentro con un 'otro", "crea una situación de diálogo en donde surgen las singularidades de cada una de las personas que intervienen o participan, aunque provocando una transformación de ambas realidades" (Battista, 2021: 47). Pensando en la relación entre arte, estética y salud mental, Suely Rolnik plantea que el arte es "una práctica de problematización (...) una práctica de interferencia directa en el mundo" (Rolnik, 2006, 3). Esta forma de concebir y practicar arte restituye el aspecto estético a la subjetividad, lo cual implica devolver la experiencia de participar en la creación y transformación de la existencia, darle un sentido vivificante a la misma. El arte, definido de esta forma, puede ser empleado como recurso en la clínica, siempre y cuando provoque la apertura de la subjetividad a lo estético, a la transformación, al devenir-otro-desí y del mundo (Rolnik, 2003: 6).

La segunda razón para incluir la construcción y teatralización con títeres surge de los trabajos realizados por Rojas-Bermúdez en el hospital Borda de Buenos Aires, en donde integró la técnica del teatro de títeres con la terapia psicosocial (1985). Una de las características que más resalta el autor acerca de la dramatización con títeres es que los mismos pueden actuar como intermediario entre quien cuenta la historia y la audiencia, algo que en el trabajo con pacientes psiquiatrizados favorece la interacción cuando las habilidades sociales se han disminuido. La intermediación del títere deriva en una proyección de la persona en el mismo, facilitando el distanciamiento de aquellas situaciones o problemáticas que están siendo narradas (1985).

En su trabajo The Ethnofiction in Theory and Practice (2006) Sjöberg retoma el concepto de etnoficción de Jean Rouch y analiza las implicancias teórico-metodológicas de utilizar esta técnica en su etnografía para explorar no solo la vida cotidiana de las personas sino también sus sueños y deseos. La etnoficción se crea a partir de la improvisación cinematográfica y actoral, en donde la cámara actúa como un agente que provoca, sin un esquema estricto de realización. Se elabora sobre las experiencias vividas, en base a temas conversados, pero sin revivir escenas experimentadas en la vida real (Sjöberg, 2006). De esta manera, los deseos, valores y representaciones de un colectivo o una persona sirven como materia prima para crear este objeto de arte que se proyecta fuera de nosotros. Tomando el concepto de performatividad como aquella dramatización reiterada que puede transformar la materialidad de nuestros cuerpos y que construye subjetividades, Sjöberg propone hablar de performatividad proyectada, en tanto que en la creación de estos productos (títeres, videos, imágenes) podemos proyectar nuestros deseos, valores y emociones al punto de transformar nuestra realidad (2006). En este sentido la elaboración de títeres y las historias que los acompañaron ha operado con la lógica de la etnoficción y la performatividad proyectada planteadas por este autor. La improvisación sobre historias vividas y repertorios culturales dio lugar a relatos capaces de transformar la autopercepción y la imagen construida por el dispositivo psiquiátrico. 


\section{Las lógicas de exclusión manicomial en el hospital}

Comencemos con algunas de las prácticas que podrían considerarse estrictamente del dispositivo psiquiátrico: la creación de diagnósticos y la categorización constante, la institucionalización de la vida cotidiana (Goffman, 2001) y la creación de relaciones de poder basadas en una microfísica de la moral (Foucault, 2008a).

Pablo es oriundo de Machala (Provincia El Oro), tiene 33 años, y a pesar de que lleva varios años institucionalizado, espera poder salir del hospital y asentarse en una vida rural. La primera vez que Pablo quiso participar del taller, una psiquiatra nos encontró en nuestro recorrido hacia el auditorio y nos advirtió lo siguiente: "cuidado que hoy de mañana Pablo tuvo convulsiones". Al preguntar sobre este tema a otro médico, se me advirtió que Pablo, si bien sufre de epilepsia, también suele "simular sus convulsiones", "es histriónico". En palabras del médico: "Las intervenciones psicológicas no han sido para nada la especialidad del hospital. No ha habido mayor profundización sobre por qué tiene estos comportamientos." (Entrevista con la investigadora, 11 de septiembre de 2020).

Lo que el hospital señalaba como histrionismo, en el taller se vivía como juegos, provocaciones, improvisaciones, dramatizaciones de los relatos. Pablo contaba historias como si las estuviéramos viviendo en ese momento, movía su cuerpo en gestos, ademanes, interpretaciones de lo que sucedía. Era en este espacio y frente a sus espectadoras que Pablo lograba captar y encauzar su persona, ponerse en relación con otros, sin la mirada patologizante y disciplinadora del discurso psiquiátrico.

En una ocasión, Pablo ejerció un rol de coordinación en la sesión de expresión corporal, poniendo a disposición un cuerpo "no enfermo". Como la mayoría de los encuentros, habíamos comenzado con una actividad de relajación corporal, en donde nos disponíamos en círculo y realizábamos una serie de movimientos dictados por mí y con los ojos cerrados. Ni bien comenzamos Marcia, una de las participantes, comenzó a quejarse de que tener los ojos cerrados y hacer determinados movimientos le mareaba, ante lo cual fui modificando los movimientos para su mayor comodidad. Luego observé que Pablo estaba realizando movimientos por su parte, y que el resto le estaba mirando. Al ver que Sylvia repetía sus movimientos, pedí que todas siguiéramos a Pablo, a lo que Marcia contestó que con los ojos cerrados no se podía. La secuencia de movimientos que realizaba consistía en extender los brazos, juntarlos en un rezo, arquear la espalda, bajar hasta las rodillas, volver al rezo, extender los brazos y volvía a comenzar. Cuando terminamos le agradecí diciendo que me había relajado, a lo cual Marcia coincidió conmigo.

Generalmente, el humor de Marcia intercedía mucho en su participación en estas actividades y repetía constantemente que no le gustaba "andar inventando cosas" (por el ingrediente de la improvisación). Por su parte, Sylvia y Cristina se entusiasmaban por momentos y otras veces simplemente se quedaban paradas y observado.

La importancia de este hecho radica en dos cuestiones: la primera que Pablo puso a disposición un cuerpo sin convulsiones ni simulacros, sin dolor y sin temblores (recurrente en todos los participantes) para el resto del taller. Un cuerpo dispuesto a transmitir sentidos y emociones, a pesar de la medicalización y la categorización constante. Y sobre todo un 
cuerpo a disposición del trabajo colectivo. La segunda cuestión importante es la respuesta que tuvo por parte de sus compañeras. Primero que las tres aceptaron seguir sus movimientos, cada una a su manera. Segundo que provocó en Sylvia la voluntad de proponer ella misma una secuencia de movimientos, una vez que Pablo terminó. Y tercero, Marcia, que no estaba de humor para esa actividad (los mareos y luego el llamado de atención sobre los ojos cerrados), estuvo de acuerdo conmigo en presentar una sensación de bienestar luego de la secuencia.

La categorización, el análisis y el registro constante dentro del hospital psiquiátrico es una práctica que encuentra distintos puntos de anclaje a lo largo del desarrollo de la psiquiatría. Luego de la aparición de Pinel en La Salpêtrière en 1792 y la liberación de las cadenas de los locos, comienza a entenderse a los locos como enfermos mentales cuya cura se garantizará a partir del ejercicio del poder disciplinario, un poder ejercido de manera capilar y que afecta hasta el más mínimo detalle de nuestra existencia (Foucault, 2008b). Este poder, que se presenta de manera difusa y es ejercido con diferentes intensidades y por relevos, se relaciona directamente con sujetos individualizados y cuerpos sujetados. Operará constantemente (a diferencia del poder soberano que se manifiesta en ceremonias y rituales de afirmación), ejerciendo una observación total, y ocupando el cuerpo y la vida del individuo. Para que esto suceda, se creará todo un tejido de escritura que produce y rodea los sujetos, registrándolos y etiquetándolos constantemente (2008b). Este "panoptismo pangráfico" se servirá de la confesión como práctica de conocimiento y ejercicio de individualización nacida a partir del siglo XX como parte de la scientia sexualis (Foucault 2015), algo que será incorporado en Ecuador por los médicos psiquiatras para la misma época con el interrogatorio (Landázuri Camacho, 2008).

Esta práctica de registro constante dentro del dispositivo de poder viene acompañada de categorizaciones normativas que producen los sujetos de la institución. La reiteración del discurso normativo (la categorización constante) ocurre puesto que los cuerpos y el sujeto se resisten a esa completitud y coherencia que definen los procesos de subjetivización (Butler, 2002). Las categorías de histriónico y simulador descontextualizan, individualizan y patologizan la persona de Pablo. Sin embargo, el sujeto encuentra nuevamente una forma de resistir a estos discursos normativos y performativos: un acontecimiento en el que las múltiples disposiciones de la norma fueron contestadas, contrarrestadas e incluso invertidas por el trabajo colectivo y una nueva disposición de los cuerpos. Pablo, cuyo cuerpo y subjetividad son constantemente etiquetados en el diagnóstico de enfermedad y de simulacro, se transformó en coordinador de cuerpos y provocó una nueva disposición en sus compañeras.

Otro soporte donde Pablo pudo construir otro relato de sí mismo fue el títere a través del cual se presentaba y conversaba acerca de sus anhelos, como casarse con una mujer y trabajar en el campo cuidando animales y cosechando sus siembras. Este títere, que llevaba el mismo nombre que Pablo, no tenía convulsiones, no tenía dolor de cabeza, no simulaba nada. Al contrario, el personaje que improvisaba a través del títere era inquieto, entusiasta y tenía proyectos en mente. 
Continuando con los efectos de la norma en el marco del dispositivo psiquiátrico, la institucionalización de la vida cotidiana ${ }^{2}$ conlleva la constitución de los (mal) llamados pacientes crónicos. Estos son aquellos que han perdido habilidades sociales a causa de internaciones de larga duración, tratamientos farmacológicos constantes y, en algunas ocasiones desmedidos, empobrecimiento a causa del estigma, descomposición de las redes sociales fuera del hospital, falta de políticas públicas que promuevan la salud mental colectiva y comunitaria, y disposiciones discursivas y extradiscursivas que asumen la necesidad de tutelar a los pacientes psiquiátricos bajo la idea de discapacidad mental y de peligrosidad (Amendolaro, 2013). En el 2013, cuando se trasladaron los últimos pacientes del Hospital Psiquiátrico San Lázaro ${ }^{3}$ (a partir de ahora HPSL) al HEJE (entre ellos Pablo y Sylvia), se conformó una "brigada de reinserción" destinada a buscar y analizar posibilidades de externación. Durante el tiempo que operó esta brigada, se lograron reinsertar 37 pacientes, sin embargo, esta fue una tarea que en muchos casos resultó en una reinstitucionalización dado que los pacientes fueron enviados a asilos, por descomposición de los lazos sociales fuera del hospital, por incapacidad por parte de las familias de sostener el vínculo con el paciente y la falta de atención comunitaria en salud mental que acompañe esa reinserción.

La idea de cronicidad demuestra el sentido excluyente de la institución psiquiátrica y revela la relación existente entre lógicas manicomiales y pobreza señalada en 1979 por Franco Basaglia (2008). Según el autor "la psiquiatría es desde su nacimiento una técnica altamente represiva, que el Estado siempre usó para oprimir a los enfermos pobres, es decir la clase trabajadora que no produce" (2008: 26). Hoy día, siguen imperando técnicas de castigo y reglamentaciones forzadas que dictan la vida de los pacientes psiquiátricos y los convierte en sujetos cada vez más alejados de su emancipación (2008).

Por otro lado, hay una relación directa entre institucionalizaciones prolongadas y desigualdad de género, algo que profundizaré más adelante. Sin embargo, cabe destacar el trabajo realizado por Ramírez (2011) en donde analiza el ingreso, la permanencia y el tratamiento diferencial que opera sobre mujeres y hombres en un hospital psiquiátrico de Quito, postulando la perspectiva de género como crucial para pensar la institucionalización en hospitales psiquiátricos.

En el caso de Sylvia, que lleva más de 20 años institucionalizada (entre el HPSL y el HEJE) su "cronificación" indica más bien un alto grado de institucionalización con tratos

\footnotetext{
${ }^{2}$ Goffman (2011) define institución total como aquellas instituciones en las que residen personas, excluidas de la sociedad por el peligro que representan, y cuyas vidas cotidianas están totalmente mediadas por reglas de espacios, tiempos y comportamientos.

${ }^{3}$ El Hospital San Lázaro (Landázuri Camacho 2008), ubicado en las afueras del centro histórico de la ciudad de Quito, cerró sus puertas en el año 2013 tras convertirse en un Centro de Atención Ambulatoria Especializado. Los pacientes que aún permanecían en este espacio fueron trasladados a otras instituciones como el Hospital Especializado Julio Endara, entre ellos los participantes del taller, Sylvia y Pablo. El cierre del San Lázaro se vincula a un intento de reformular la atención en salud mental, sin embargo, muchos de los pacientes que allí residían sufrieron reinstitucionalizaciones en vez de una reinserción verdadera en la comunidad. Hoy día, Ecuador dispone de un Plan Estratégico Nacional y un Modelo de Atención en Salud Mental 2015-2017 que propone una atención comunitaria de salud mental enfocada en la atención primaria, sin embargo, no ha conducido a una mejora significativa (Camas Baena 2018).
} 
denigrantes como el tutelaje y el castigo. En Riobamba, provincia rural de donde es oriunda, trabajaba en el restaurante "Las gaviotas" y hacía servicio de mesa. En el HPSL Sylvia solía realizar tareas de aseo como el trapeo de pisos, el cambio de fundas de basura y el traslado de ropa sucia. Hoy día, su participación en los talleres se encuentra intervenida por la idea de que no es capaz de hacer determinadas cosas y cada vez que trabajábamos en la construcción de títeres Sylvia pedía que hiciéramos por ella: “Cómo hago? ¿Cómo hace? A ver, haga usted” decía. A su vez, las consignas de improvisación teatral y expresión corporal le resultaban difíciles de seguir, lo cual implicaba un trabajo mucho más pausado, aunque no clausurado. A pesar de que el hospital había logrado contactar un hijo de ella, Sylvia se negaba a salir y vivir con él: "estoy enseñada ${ }^{4}$ con el hospital" decía, "afuera tengo que ir a hacer las compras, hacerme la comida...y mi hijo vive en un 4to piso, no se no más que querrá hacer”. De manera que ella también incorporaba el discurso de su "discapacidad” y dependencia con el hospital.

Además de ciertos comportamientos violentos por parte de algunos enfermeros (tomar del brazo fuertemente, empujar, hablar duramente), lo cual invita a una investigación más profunda, los y las residentes del hospital, en especial los llamados pacientes crónicos, son tratados de "niños" o "wawas" (niños o niñas en kichwa), sus horarios de descanso y alimentación son estrictos y unánimes para todos, son aseados y cada una de sus actividades y recorridos del hospital calculados. Durante el tiempo que sostuvimos los encuentros de taller, mi tarea era buscar uno por uno, ir al auditorio y "devolverlos" a la sala a tiempo para la colación. Mi compromiso con el personal del hospital era que yo "los cuidaría” y "me haría cargo de cualquier cosa que sucediera estando conmigo". Un sentido de peligrosidad y de discapacidad imperaba en cada uno de estos gestos y reproducía la idea de que los y las residentes no tienen autonomía para tomar decisiones y deben ser tutelados.

En cuanto a los castigos, Sylvia se encontraba castigada las primeras dos veces que hicimos el taller. Si bien consistía en no poder salir de la sala o no poder asistir a terapia ocupacional, constituyéndolo en un castigo "suave", este sostiene la práctica de subyugación e infantilización de los pacientes. Sylvia había sido castigada por el personal de terapia ocupacional, y la enfermera de la sala fue la que concedió el permiso para ir a mi taller, de manera que su tutelaje fue negociado entre el personal médico y mi persona, excluyendo a Sylvia de la toma de decisión e instalando de alguna manera la obediencia agradecida. En este sentido, el castigo tiene pie en las antiquísimas prácticas del disciplinamiento psiquiátrico, en donde el paciente se encuentra con un ejercicio del micropoder repartido en distintos personajes y performa una obediencia agradecida con el médico (Foucault, 2008a).

\section{El otro interno y la alteridad total en el hospital psiquiátrico}

Hablé anteriormente de la relación establecida entre psiquiatrización y pobreza no solo como condición común al momento de ingresar a los hospitales sino también el empobrecimiento como consecuencia de la estigmatización, la disolución de lazos extramuros, procesos de institucionalización extremadamente largos y la falta de políticas

\footnotetext{
${ }^{4}$ Estar enseñada con" es una frase común utilizada para indicar que una persona está acostumbrada a algo (lugar, comida, relaciones etc.).
} 
públicas que atiendan a la reinserción de los pacientes externados. Sin embargo, es necesario pensar los procesos de empobrecimiento y de institucionalización psiquiátrica en relación los procesos de construcción del Estado-nación ecuatoriano, y la consecuente subalternización de las comunidades indígenas y negras propia de la persistencia de la colonialidad del poder (Quijano, 2014).

La persistencia de la colonialidad del poder, es decir, la racialización y exclusión de los sectores de la población reconocidos como no blancos luego de la proclamación de la independencia de los estados colonialistas europeos en Latinoamérica configuró un paisaje racista y de desigualdad de género que invisibilizó y condenó a la pobreza a estos sectores (Quijano, 2014). En este sentido, los procesos de construcción de los estados-nación postcoloniales fueron acompañados por discursos identitarios nacionales basados en la construcción y exclusión del otro interno. Estas construcciones se basan sobre la jerarquización étnica, racial, de género y de clase propias de la colonia y decantadas, naturalizadas y vueltas discurso identitario nacional en el desarrollo de los estados latinoamericanos "postcoloniales". Este discurso adquiere diferentes matices y elementos étnicos para poder erigirse, pero siempre postula a la población blanco-mestiza adulta como la referente principal de la nacionalidad, justificando su posición socioeconómica, su representación mayoritaria en el gobierno y el empobrecimiento de las clases subalternas.

En Ecuador los intentos de desarticulación de las poblaciones originarias y su reacomodación en un régimen colonial fue configurando, especialmente en las tierras altas, el régimen de hacienda como sistema de dominación social, cultural y económico, basado en jerarquías racializadas (Breton, 2012). El régimen de hacienda se configuró desde mediados del siglo XVII y conformaba un sistema denso de relaciones horizontales y verticales atravesadas por una economía moral, paternalista y racista, volcada a sostener el poderío económico, social y cultural de la clase alta ecuatoriana (Bretón 2012). Luego de inicios de siglo XX Ecuador experimentó una serie de transformaciones tecnológicas comunicacionales y de transporte, y una migración ruralidad-ciudad que provocó el despliegue de toda una serie de estudios científicos, políticas públicas y discursos orientados a reconocer, catalogar y controlar aquella población heterogénea que desordenaba, afeaba y ponía en peligro la ciudad y los valores de la clase alta ecuatoriana. Bajo la carátula de mestizaje se impulsó un proceso por el cual se invisibilizó la población indígena y negra y se disimularon las relaciones de poder colonial que aun articulaban clase, etnia, género, sexo y raza de manera desigual. Según Peter Wade (2003) el mestizaje puede definirse como una ideología nacionalista en Latinoamérica que ha impulsado un proceso de homogeneización de cara a la economía internacional, aunque manteniendo una heterogeneidad suficiente que permite sostener las desigualdades de clase. En cada país, este proceso ha significado el blanqueamiento de la población nacional mediante la exclusión de los elementos indígena y negro.

Parte de las políticas y prácticas de construcción e invisbilización del otro interno, son las llamadas políticas higienistas, las cuales, guiadas por una mirada racista y clasista, se destinaron a "adecentar las ciudades" (Kingman, 2002). Estas prácticas y políticas higienistas, junto con el posterior desarrollo de la criminología, son el punto de encuentro histórico 
entre la constitución del otro interno de la nación ecuatoriana y la constitución del sujeto psiquiatrizado y el hospital psiquiátrico.

Según Kingman (2002) la primera etapa de las políticas higienistas sucede durante todo el siglo XIX, sin que haya políticas públicas ni organismos especializados encargados de impulsar y organizar las tareas, bajo las cuales se impulsaron prácticas de exclusión y separación, como la prohibición de vestimenta y costumbres indígenas en "espacios públicos" (como criar animales o vender comida en la calle). Los inicios del HPSL, fundado en 1785 bajo el nombre de Hospital Jesús, María y José, coinciden con esta primera etapa, y se adjudican a la necesidad de depositar aquellas personas que no cumplían con los estándares de productividad y moralidad propios de la época. Al hospicio llegaban mendigos, prostitutas, borrachos, huérfanos, enfermos de lepra y ancianos entre los cuales se camuflaban "locos" (Landázuri Camacho, 2008), similar a cómo sucedía en los viejos hospicios europeos del 1600. Esta población, producto de la crisis económica mundial y regional, no era bien recibida en las calles de la Real Audiencia de Quito y es enviada mayormente por acción de la policía (2008). Salvo los enfermos de lepra que en muchas ocasiones pertenecían a familias adineradas, la población que ingresaba al hospital pertenecía a la clase popular, compuesta por indígenas, negros y mestizos empobrecidos, los otros internos.

Hoy en día hay algunas prácticas y discursos que aún circulan y que se encargan de invisibilizar las características de definición identitaria indígena y afroecuatoriana dentro del hospital. En una conversación que tuvimos entre los participantes del taller y yo, mientras definíamos el aspecto final de los títeres, me comentaron que cuando Cristina llegó al hospital tenía trenza, pero se la habían cortado por una cuestión de higiene, puesto que "tenía muchos piojos". Quién había enviado a cortar la trenza de Cristina era su "madrina” del hospital, una enfermera que había sido asignada a Cristina como tantos otros profesionales del hospital que también fueron asignados a otros pacientes crónicos como madrinas o padrinos. Cristina es una mujer joven proveniente de la provincia El Cañar que convive junto a Sylvia y Pablo en la misma sala del hospital.

En este relato se conjugan distintas formas de producir históricamente lo otro. Primero, el argumento para "cortar la trenza" se basa en una "cuestión higiénica", tal como fueron prohibidas costumbres indígenas en la ciudad de Quito en el siglo XVIII. La procedencia de Cristina, sus rasgos faciales, su apellido y la historia de la trenza indican un origen indígena. Segundo, se presenta como un acto de afecto y de educación toda vez que la decisión que toma por y para Cristina, es mejor para Cristina; suavizando y tornando la relación de poder ambigua. La idea del apadrinamiento había surgido como forma de combatir el abandono en pacientes crónicos, los cuales, en su mayoría, no tienen visitas por parte de la familia ni otros vínculos estables por fuera del hospital. Ante la posibilidad de ver mejoras en su estado de cronicidad, instalaron ese sistema de apadrinamiento para incentivar su estimulación social. Sin embargo, siguen reproduciendo prácticas de invisibilización y estableciendo relaciones de jerarquía basadas en una moral hacendataria.

La práctica del madrinazgo o padrinazgo ha sido analizada por Cristina Vera Vega (2019) a propósito del "modelo colonial hacendatario de género" como sistema de 
administración privada del mundo indígena y afro, especialmente de las mujeres, que perpetúa el sistema de clasificación, división y opresión racista, clasista y patriarcal de tiempos de la colonia. Para que este sistema sobreviviera durante tanto tiempo, las relaciones de dominación y explotación propias de la colonia se mezclaron con un sistema de "economía moral”, en donde estas relaciones se daban de forma confusa y ambigua, mezclando figuras familiares, afectividades y tratos de servidumbre (Vega Vera, 2019). Estas figuras invisibilizaron y perpetuaron una concepción infantil y de no-ciudadanía de tiempos de la colonia sobre las mujeres indígenas y negras.

Si bien, no todos los procesos y narrativas de subjetivización tienen su contracara en algún relato otro, el relato de que Cristina tenía pelo largo y trenza, llevó a la elaboración de un nuevo relato que contradice ese acto "piadoso" e "higiénico", y que, haciendo uso de otros sustratos y otro lenguaje, permite a Cristina enarbolar su singularidad. Ya para uno de los últimos encuentros del taller, cuando estábamos creando el pelo de los títeres, Cristina dijo que su títere tendría trenza, y agregó, “a mi manera”. Este pequeño acto transita entre la experiencia vivida, el relato y la materialidad, y permite a Cristina proyectarse en el títere contradiciendo las prácticas racistas del hospital y elaborando una imagen singular y elegida por ella.

La figura del compadrazgo aparece también en un relato de Marcia, la cuarta participante del taller. Marcia es una mujer afroecuatoriana proveniente de Esmeraldas que al momento de construir una historia para su títere escribió "Las muñecas con zapatos": una historia en la que 3 niñas que vivían con sus padres "apoderados" y no tenían qué vestir, conocen un "hada madrina" que les enseña a usar distintos zapatos y finalmente, las niñas pasan de ser "muñecas" a ser "señoritas", y nunca más les falta nada.

El sistema hacendatario, del cual forma parte el compadrazgo, reproduce lógicas racistas y patriarcales propios del sistema colonial, en donde las mujeres han sido relegadas a los estratos más bajos de la sociedad, incluso al interior de cada grupo socio-racial. Este sistema posicionó al blanco-mestizo como el sujeto nacional ecuatoriano, el indígena un ciudadano a medias, y la población negra constituyó el "último Otro", expulsada del discurso identitario nacional y las mujeres negras relegadas al último escalón en relación a los varones de todos los grupos y a las mujeres blanco-mestizas (Rahier, 2003, en Vega Vera, 2019).

En el sistema hacendatario las mujeres blanco-mestizas apoderadas se encargaban de educar a las niñas indígenas y negras, construyendo una subjetividad femenina patriarcal y colonial donde las mujeres se subyugan a los hombres blanco-mestizo adultos (Vega Vera, 2019). "Las muñecas con zapatos" es una historia emplazada en el campo, en donde aparece la figura de los "padres apoderados", la educación en el trabajo doméstico (aprender a planchar, a lavar), la educación en la subjetividad "femenina" (aprender a vestirse bien cuando una ya es "mujercita") y el sufrimiento de la precariedad obligada (andar desnudas, sin zapatos). La aparición del hada madrina permite romper con esa situación angustiante de "no ser cuidadas" y enseña a las niñas a ser señoritas decentes, para "dejar de ser muñecas". Además, otorga un estatus de independencia a las niñas, algo que en el sistema hacendatario de género está vedado para las mujeres y en especial para las niñas/mujeres apadrinadas. Para contar esta historia Marcia eligió crear el títere de "Johana", una de las niñas de la historia, 
ya avanzada en edad (unos 60 años) y siendo la abuela de todos los títeres. En la historia, poder crecer, desarrollarse en una mujer adulta y posicionarse como la abuela de otros, continúa enarbolando aquella independencia y suma un sentido de autoridad y cuidado sobre otros muy peculiar. Si bien la historia toma elementos de su pasado y su bagaje cultural, ficcionarla, darle un desenlace diferente y crear el personaje que contará la historia con esas características, hace que "Las muñecas con zapatos" sea un relato intervenido por la etnoficción, en el sentido que da Sjöberg en The Ethnofiction in Theory and Practice (2006). Marcia encontró varias formas de contar este relato: entre conversaciones, a través de la escritura y narrándolo frente a una cámara a la vez que presentando su títere.

\section{Salud mental y género}

Hay algunas prácticas de disciplinamiento psiquiátrico que se tornan específicas en cuanto a las mujeres y los cuerpos feminizados dentro del hospital. Como dije anteriormente, es necesario atravesar el análisis de la institucionalización en el hospital psiquiátrico con la perspectiva de género. En su tesis de maestría de Graciela Ramírez (2011) compara los diagnósticos de los manuales médicos DSM4 o CIES10 y los analizados por la autora en las historias clínicas de mujeres internadas en el hospital donde realiza su estudio, y encuentra que, a diferencia de los diagnósticos realizados a varones, la mayoría de los diagnósticos realizados sobre mujeres son crónicos y degenerativos, así como también se basan en cuestiones sexuales y afectivas. Sus historias clínicas se basan sobre los juicios morales e intentos de disciplinar la sexualidad femenina por parte de sus familias, en vez de realizarse en base a observaciones clínicas detenidas sobre síntomas. La experiencia femenina de la internación supone además una práctica de abandono familiar más acentuada lo cual da como resultado una mayor población femenina en el hospital (Ramírez, 2011).

La primera vez que conocí a Sylvia, me comentó en susurros que estaba embarazada. Cuando pregunté acerca de esto a practicantes y profesionales del hospital, me comentaron que Sylvia había sido esterilizada puesto que, aún dentro del hospital, había estado varias veces embarazada. Por otro lado, Sylvia también recordaba un video que le habían mostrado en donde aparecía diciendo "Soy Sylvia, tengo 30 años y tengo una hija llamada Susana Trinidad" y luego cantaba un pasillo (música ecuatoriana tradicional). Este recuerdo lo traía constantemente, y llegó a tomar tanta importancia al punto que decidió nombrar Susana Trinidad a su títere.

Hay tres cuestiones que quisiera remarcar acerca de estos relatos: por un lado, la gestión de la sexualidad, la cual en personas diagnosticadas con retraso mental (como es el caso de Sylvia) y pacientes psiquiátricos, se la considera inexistente, lo cual lleva a una desinformación total sobre el tema, poniendo en riesgo la salud y los derechos de los mismos y más aún de las mujeres. Por otro lado, la falta de aplicación de los derechos reproductivos de pacientes, especialmente de pacientes mujeres en los hospitales psiquiátricos, lo cual conlleva la negación a la maternidad en las mujeres psiquiatrizadas, algo que en definitiva es una forma de disciplinamiento hacia las mismas. Y por último, el secreto a voces de que 
dentro de las instituciones de asilamiento como hospitales psiquiátricos y especializados, el abuso y acoso sexual son comunes. ${ }^{5}$

En este entramado Sylvia construye dos relatos que contradicen o contrarrestan los efectos de estas prácticas de poder, a través de su corporalidad y el títere. La idea del embarazo, transmitido entre susurros y risas, con la complicidad de su compañero, es una forma de contradecir esa norma que vuelve asexuales los cuerpos psiquiatrizados, punitiviza la sexualidad femenina y niega la maternidad a las mujeres psiquiatrizadas. Si los embarazos fueron producto de violaciones la transgresión está en poder contarlo, si fueron producto de relaciones sexuales consensuadas la transgresión está en el disfrute. Si bien es probable que no haya un embarazo en curso, el relato no deja de tener relevancia: es memoria corporal que sobreviene al presente y se hace carne en su autopercepción corporal y como transgresión a la norma.

Es un relato que se encuentra en transición entre pasado y presente, pero también entre la materialidad y lo simbólico. La experiencia material de sus embarazos se traduce en una memoria transgresora, y hay una corporización de esa memoria que restituye, o reclama restituir, la maternidad negada.

Por otro lado, nombrar al títere con el nombre de su hija es traerla a este espaciotiempo, volverla tangible, cambiar el curso de la historia. Es un relato que, producto del ir y venir con otros, se desplaza entre lenguajes y sustratos, entre el recuerdo oral y la aparición material. Es un relato otro, puesto que transforma un recuerdo, insignificante para el relato institucional, en un objeto material y protagónico que transforma la realidad.

\section{Los relatos otros: una definición}

Las posibilidades de diálogo y co-elaboración que ofrece la etnografía durante y luego del campo, sumado a este cuerpo teórico-metodológico, dieron como resultado la creación de un concepto nuevo que permitió integrar la exploración metodológica y construir una herramienta de análisis sumamente interesante. Si la premisa es dar valor a los procesos de singularización y no redireccionarlos a través de la norma, los relatos de vida, la creación de títeres y las relaciones establecidas en el taller no pueden sino ser escuchados y observados atentamente, sin establecer procesos de veridicción, sin exigir una linealidad cronológica ni una completitud y coherencia individual. Bajo esta óptica muchas de las manifestaciones, acontecimientos, diálogos, historias y relaciones establecidas en el taller, tomaron valor y arrojaron luz en la producción de singularidades.

Los relatos otros son aquellos relatos que, valiéndose de diferentes lenguajes, herramientas y sustratos, resisten, contrarrestan y desbordan los efectos de la norma. Son procesos de singularización que ponen en tensión los procesos de subjetivización. Los caracteriza la puesta en juego de una infinidad de recursos orientados por la transformación de las realidades y el agenciamiento. Varían desde la creación de imágenes desde la

\footnotetext{
${ }^{5}$ Entre las problemáticas relatadas en el informe realizado sobre un hospital psiquiátrico de Buenos Aires (CELS, 2017) se encuentran el sometimiento a esterilizaciones y abortos no consensuados; negación del derecho a maternar; condiciones socioeconómicas que impiden una externación garantizada especialmente en mujeres; tratos y relaciones estigmatizantes por parte del personal.
} 
corporalidad, la fotografía, el video, la creación de objetos, la creación de cuentos, historias, el canto y las creaciones colectivas. La elección del nombre "relatos otros" hace referencia al trabajo realizado desde la construcción de relatos y la acción de resistencia que presentaban frente a las narrativas institucionales.

Este concepto constituye una herramienta de análisis que permite comprender la coexistencia de estos dos procesos de subjetivación: aquel modelado por la norma y que sujeta los cuerpos y los vuelve individuales, y aquel que acontece constantemente y nos vuelve singulares, diferentes, incompletos y performáticos. Así como los procesos de subjetivización de la norma se hacen presentes en discursos y prácticas extradiscursivas que construyen el sujeto psiquiatrizado, también hacen su aparición los procesos de singularización del sujeto que resiste, que se vale de múltiples recursos para correrse del cuerpo sujetado (Foucault, 2008b), y que construye imágenes que crean otro relato de sí mismos.

\section{Conclusiones}

Los resultados aquí expuestos buscan explorar el argumento que llevó a pensar las tensiones existentes entre procesos de subjetivización y procesos de singularización dentro del hospital psiquiátrico. Así mismo, quise destacar el corpus metodológico empleado para poder llevar a cabo la investigación, orientado especialmente para reconocer y dar valor a los procesos de singularización que acontecen dentro del hospital y señalar pistas para direccionarlos hacia procesos de transformación de las prácticas, relaciones y discursos que definen el campo de la salud mental en Quito.

En la etnografía fue posible reconocer cómo las prácticas de poder del dispositivo psiquiátrico son atravesadas a su vez por otras prácticas provenientes de la subalternización e invisibilización de poblaciones indígenas y negras propias del sistema colonial, y de las prácticas y discursos de poder provenientes del sistema de desigualdad de género (que a su vez tienen también su ancla en el sistema colonial). Estas intersecciones vuelven aún más complejas las experiencias de institucionalización de las personas y construyen distintas capas de subjetivización, manteniéndolas en lugares de opresión y resistencia. Las formas que encuentran los participantes del taller de contradecir, contrarrestar o esquivar estas prácticas y discursos de poder, encuentran asidero en las distintas propuestas del taller: el juego de la corporalidad, la escucha atenta en los relatos, la creación de títeres e historias ficcionadas, la creación de imágenes fotográficas, la interacción con la cámara de video. Muchos de sus relatos ya existían desde antes del taller, sin embargo, el espacio, las herramientas y lenguajes puestos en juego y mi labor como antropóloga, permitieron reconocerlos, pensarlos en relación a las problemáticas socioculturales y valorizarlos como procesos de singularización, en vez de problemas individuales.

Los vistazos realizados sobre la historia del HPSL, su relación con el higienismo y las políticas de invisibilización del otro permiten reconstruir históricamente la actualidad de las prácticas y discursos que circulan dentro HEJE. Así mismo, he traído a discusión la forma en que la institucionalización psiquiátrica y el género se intersectan, con la intención de dar 
importancia a estos estudios tan necesarios para desarmar las distintas formas de opresión que viven especialmente las mujeres psiquiatrizadas.

El concepto de relatos otros ha surgido en el proceso de investigación como herramienta de análisis que involucra tanto el reconocimiento de los procesos de singularización, la relación no siempre directa ni coherentemente contradictoria con los procesos de subjetividad y la enorme posibilidad de desplazamiento entre distintos sustratos, herramientas y lenguajes para poder tener lugar. La transformación de los cuerpos frente a la categorización constante e intervención desmedida de la medicina, la colectivización de esa transformación, la construcción de relatos con otros, la performatividad proyectada sobre el cuerpo y personalidad de los títeres, la memoria corporal como soporte de las transgresiones y la restitución de aquello que ha sido negado, y que no tiene vuelta atrás en el plano material, el títere como soporte de denuncia y de reconstrucción de la identidad negada e invisibilizada en relaciones de poder ambiguas.

Con este trabajo espero haber realizado una revisión crítica sobre las prácticas y discursos anquilosados dentro y fuera del hospital psiquiátrico que vuelven al sujeto psiquiatrizado una alteridad total, en relación de dependencia, observados y constituidos como un todo cohesionado definido por la enfermedad, la carencia, la incapacidad y la peligrosidad. Así mismo, pensar el empobrecimiento de las clases subalternizadas y la institucionalización de sus vidas, como procesos atravesados por prácticas discursivas y extradiscursivas racistas, de exclusión étnica y de desigualdad por género.

Es necesario que las relaciones que se establecen dentro del hospital abran espacio para el vacío, para que lo otro diferente acontezca y para que los procesos de subjetivización conformen procesos de transformación y no de sujeción. Que las herramientas puestas en práctica abracen y potencien la diversidad que nos constituye como personas en vez de negar e invisibilizar, achatar la diferencia y domesticar las subjetividades. Que comience a gestarse una mirada crítica que observe y revierta el disciplinamiento, no solo psiquiátrico sino también de género y racista, que opera como práctica corriente dentro del hospital.

\section{Referencias}

AMENDOLARO, Roxana. 2013. "Entre el diagnóstico de cronicidad y el fenomeno de la discapacidad desde una perspectiva de Derechos Humanos". Salud mental y comunidad, a. 3, n. 3: 19-28.

BASAGLIA, Franco. 2008. La condena de ser pobre y loco: alternativas al manicomio. Buenos Aires: Topía.

BOURDIEU, Pierre. 1997. "La Ilusión biográfica”. En: Bourdieu, Pierre. Razones prácticas. Barcelona: Anagrama.

BOURRIADU, Nicolas. 2008. Estética relacional. Buenos Aires: Adriana Hidalgo.

BRETON SOLO DE ZALDÍVAR, Víctor. 2012. Toacazo. En los Andes equinocciales tras la

Reforma Agraria. Quito: FLACSO: Sede Ecuador; Ediciones Abya Yala; GIEDEM; Universitat de Lleida. 
BUTLER, Judith. 2002 [1993]. Cuerpos que importan. Sobre los límites materiales y discursivos del "sexo". Buenos Aires: Paidós.

BUTLER, Judith. 2009. Dar cuenta de sí mismo. Buenos Aires: Amorrortu.

CENTRO DE ESTUDIOS LEGALES Y SOCIALES. 2017. La situación de las mujeres en el hospital psiquiátrico Dr. Alejandro Korn "Melchor Romero. Buenos Aires: CELS.

DELEUZE, Gilles. 2008. Dos regímenes de locos. Valencia: Pre-textos.

DELEUZE, Gilles. 2015. La subjetivación: curso sobre Foucault III. Buenos Aires: Cactus.

DELEUZE, Gilles; GUATTARI, Félix. 1985 (1972). El Anti Edipo. Capitalismo y esquizofrenia. Barcelona: Paidós.

FOUCAULT, Michel. 2003. Historia de la sexualidad 2: El uso de los placeres. Buenos Aires: Siglo XXI.

FOUCAULT, Michel. 2005. Historia de la sexualidad 1: La voluntad de saber. Madrid: Siglo XXI.

FOUCAULT, Michel. 2008a. El poder psiquiátrico. Curso en el College de France (19731974). Buenos Aires: Fondo de Cultura Económica.

FOUCAULT, Michel. 2008b. Tecnologías del yo. Buenos Aires: Paidós.

FOUCAULT, Michel. 2015. Historia de la Locura en la epoca clásica - Vol 1. Mexico DF: Fondo de cultura económica.

GOFFMAN, Erving. 1974. Manicômios, prisões e conventos. Sao Paulo: Perspectiva.

GOFFMAN, Erving. 2001. Internados. Ensayos sobre la situación social de los enfermos mentales. Buenos Aires: Amorrortu.

GUATTARI, Felix; ROLNIK, Suely. 2006. Micropolitica. Cartografias del deseo. Madrid: Traficantes de sueños.

INGOLD, Tim. 2015. "Conociendo desde dentro. Reconfigurando las relaciones entre la antropología y la etnografía”. Etnografias Contemporáneas, n.2: 218-230.

JELIN, Elizabeth. 2002. Los trabajos de la memoria. Madrid: Siglo XXI.

KINGMAN, Eduardo. 2002. "Historia social y mentalidades: los higienistas, el ornato de la ciudad y las clasificaciones sociales”. Íconos, n. 15: 104-113. DOI: 10.17141/iconos.15.2003.559

KINGMAN, Eduardo. 2002. "Identidad, mestizaje, hibridación: sus usos ambiguos". Proposiciones, n. 34: 1-8.

LAGO, Laura. 2015. El taller como dispositivo en salud. Guía teórica-practica para talleristas. Buenos Aires: Subsecretaría de salud mental y atención a las adicciones.

LANDÁZURI CAMACHO, Mariana. 2008. Salir del encierro. Medio siglo del Hospital Psiquiátrico San Lázaro. Quito: Banco Central del Ecuador.

MARTINS, Paulo Henrique. 2018. "La actualidad de la Teoría del Colonialismo Interno para el debate sobre la dominación y los conflictos inter-étnicos”. En: BIALAKOWSKY, Alberto L.; BONILLA, Nora Garita; CATHALIFAUD, Marcelo Arnold; MARTINS, Paulo Henrique; CORONADO, Jaime A. Preciado. (Comps.). Las encrucijadas abiertas: América Latina y Caribe. Buenos Aires: Abya Yala, pp. 311-334.

PELBART, Peter. 1989. Da clausura do fora ao fora da clausura. Loucura e desrazão. São Paulo: Editoria Brasiliense. 
QUIJANO, Aníbal. 2014. Cuestiones y horizontes: de la dependencia histórico-estructural a la colonialidad/descolonialidad del poder. Antología esencial. Buenos Aires; Lima: CLACSO; Universidad Nacional de San Marcos.

RAMÍREZ, Gabriela. 2011. Encierro, patología y género: los sujetos de la exclusión psiquiátrica. Quito: FLACSO-Ecuador.

ROJAS-BERMÚDEZ, Jorge. 1985. Titeres y sicodrama. Buenos Aires: Editorial Celsius.

ROLNIK, Suely. 2006. ¿El arte cura? Barcelona: MAC-BA

VERA VEGA, Cristina. 2019. Hijas del viento - Wayra Apamushkas: Historias de vida de mujeres entregadas de niñas para el trabajo del hogar en los Andes ecuatorianos. Ciudad Autonoma de Buenos Aires: Antropofagia.

VIGANLI, Silvana. 2014. "Políticas de la vida y estética de la existencia en Michel Foucault". Praxis Filosófica, n. 37:169-192.

WADE, Peter. 2003. "Repensando el mestizaje”. Revista Colombiana de Antropología, vol. 39: 273-296. DOI: 10.22380/2539472X.1243

resumo Neste artigo apresento uma análise antropológica que procura reconhecer as diferentes formas pelas quais os processos de subjetivação e singularização estão em constante tensão dentro do Hospital Especializado Julio Endara em Quito. Para isso, vou recorrer ao trabalho etnográfico realizado no âmbito de uma oficina de fantoches e histórias de vida com os residentes do hospital. Ela lança luz sobre a sobreposição de exclusões de raça, classe, gênero e o mundo da razão experimentado por pacientes psiquiátricos. Elaboro o conceito de outras narrativas através das quais identifico processos de singularização, na transição entre diferentes idiomas, substratos e ferramentas de elaboração. Espero apresentar uma visão antropológica do mundo da saúde mental, uma abordagem integral e situada capaz de oferecer, numa chave transdisciplinar, alternativas à lógica da saúde mental psiquiátrica que ainda prevalece dentro e fora dos hospitais psiquiátricos.

palabras-chave Subjetividade; singularidade; saúde mental; etnografia; hospital psiquiatrico

\section{sobre la autora}

\section{Malena Battista}

Licenciada en Antropología, recibida de la Facultad de Ciencia Naturales y Museo, de la Universidad Nacional de La Plata. Realizó estudios de artes audiovisuales, salud mental, género y educación no formal.

Declaración de Autoría: La autora fue responsable por la recogida, sistematización y análisis de los datos, así como de la escritura del artículo.

Financiación: La escritura de este artículo no contó con beca de apoyo a la investigación.

Recibido en: 26/06/2021

Fecha de aceptación 22/10/2021 